\title{
Management of the Hospitalized Transplant Patient
}

\author{
Brian Boerner • Vijay Shivaswamy • Whitney Goldner • \\ Jennifer Larsen
}

Published online: 27 February 2015

(C) The Author(s) 2015. This article is published with open access at Springerlink.com

\begin{abstract}
Significant hyperglycemia is commonly observed immediately after solid organ and bone marrow transplant as well as with subsequent hospitalizations. Surgery and procedures are well known to cause pain and stress leading to secretion of cytokines and other hormones known to aggravate insulin action. Immunosuppression required for transplant and preexisting risk are also major factors. Glucose control improves outcomes for all hospitalized patients, including transplant patients, but is often more challenging to achieve because of frequent and sometimes unpredictable changes in immunosuppression doses, renal function, and nutrition. As a result, risk of hypoglycemia can be greater in this patient group when trying to achieve glucose control goals for hospitalized patients. Key to successful management of hyperglycemia is regular communication between the members of the care team as well as anticipating and rapidly implementing a new treatment paradigm in response to changes in immunosuppression, nutrition, renal function, or evidence of changing insulin resistance.
\end{abstract}

Keywords Diabetes mellitustype 1 -Diabetes mellitus type 2 . Organ transplant $\cdot$ Kidney transplant $\cdot$ Heart transplant $\cdot$ Bone marrow transplant $\cdot$ Hyperglycemia $\cdot$ Rejection $\cdot$ Diabetes complication

This article is part of the Topical Collection on Hospital Management of Diabetes.

B. Boerner $\cdot$ V. Shivaswamy $\cdot$ W. Goldner $\cdot$ J. Larsen Division of Endocrinology and Metabolism, Department of Internal Medicine, UNMC and VA Nebraska-Western Iowa Health Care System, Omaha, NE 68105, USA

J. Larsen $(\bowtie)$

987878 Nebraska Medical Center, Omaha, NE 68198-7878, USA

e-mail: jlarsen@unmc.edu

\section{Introduction}

Surgeries of all kinds and post-operative pain have been long shown to increase risk of hyperglycemia by triggering cytokines and stress hormones known to aggravate insulin action [1]. Thus, it is not surprising that hyperglycemia occurs after major operations required for solid organ transplant. But, as the numbers of solid organ transplants and bone marrow transplants performed each year continue to grow, and transplant recipients live longer, more transplant patients will require management of glucose not only after their initial transplant procedure but also after subsequent hospitalizations for episodes of care that may or may not be related to their transplant. Current immunosuppression regimens contribute to hyperglycemia in organ transplant patients, as does preexisting risk.

Diabetes is common among transplant candidates, but some recipients are first recognized as having diabetes only after transplant. Diabetes that is first diagnosed after transplant, previously called New Onset Diabetes After Transplantation (NODAT), may be new onset but could also represent previously unrecognized diabetes, so a recent international consensus panel suggested changing the name to posttransplant diabetes mellitus (PTDM) [2, 3•]. Hyperglycemia is also common immediately after solid organ and bone marrow transplant, with a frequency reported at $80-90 \%$ or more for kidney transplant recipients in the first days to week following transplant $[4,5 \cdot]$ but may resolve after immunosuppression doses are reduced. Thus, the diagnosis of PTDM should be reserved for hyperglycemia that persists after the recipient has been reduced to maintenance immunosuppression doses. The incidence of PTDM using these new guidelines is as yet unknown, but the increasing frequency of obesity, the significant impact of current immunosuppression regimens on insulin secretion and action, and the greater scrutiny of glucose control in all hospitalizations have led to the 
recognition that significant hyperglycemia is very common in the immediate post-transplant hospitalization.

With this background, whether treating preexisting diabetes, post-transplant diabetes, or new hyperglycemia that may be diagnosed as post-transplant diabetes at a later time, management of hyperglycemia in the transplant patient is common and important. This chapter will focus on the contributing factors to hyperglycemia in the hospitalized transplant patient, the current knowledge about outcomes and consequences of uncontrolled hyperglycemia after transplant, goals for glucose control, and practical strategies and considerations for glucose management in these populations, including the need to plan for care transitions to home after hospital discharge.

\section{Transplant-Related Factors that Contribute to Altered Glucose Metabolism in the Hospitalized Transplant Patient}

Preexisting Insulin Resistance and Glucose Intolerance, Including Post-Transplant Diabetes Mellitus Frequency of impaired glucose tolerance and diabetes is already high in transplant populations. Diabetes is the most common cause of endstage renal disease and need for kidney transplant in the USA [6-8]. Diabetes is also present in 14-22 \% of heart transplant recipients [9-11] and up to a quarter of liver transplant recipients $[12,13 \bullet]$. Obesity is also very common in transplant populations. Up to $60 \%$ or more of kidney transplant recipients are overweight or obese at the time of transplant [14], and further weight gain after transplant is common, which can exacerbate hyperglycemia [15]. Obesity in the organ transplant recipient is directly linked to insulin resistance, as shown in kidney transplant recipients, where risk for hyperglycemia is associated with body mass index, though not necessarily in the immediate post-operative period after transplant $[16,17]$.

PTDM, as defined by older 2003 guidelines [2], is estimated to occur in 17 to $74 \%$ of kidney transplant recipients, up to $30 \%$ of liver transplant recipients, and approximately a quarter of heart transplant recipients [18-23]. Newer consensus guidelines suggest that delaying diagnosis until persistent hyperglycemia is demonstrated after the recipient has been reduced to maintenance immunosuppression doses (Table 1) [3•]. While hemoglobin A1c has been added as a diagnostic criteria for diabetes by the American Diabetes Association for diagnosis in the general population, it is associated with an unacceptable false-negative rate for diagnosis of diabetes after transplant due to the frequency of anemia and transfusion so should not be as the sole screening criteria in the first year after transplant [24]. It should be noted that even with regular screening for diabetes, transplant patients can develop interval PTDM that may remain asymptomatic and unrecognized until they are hospitalized for another cause.
Table 1 Diagnosis of post-transplant diabetes mellitus

Diagnosis of post-transplant diabetes mellitus is similar to the diagnosis of diabetes in non-transplant populations, where the testing should be performed outside of the hospital, with no recent history of restricted nutrition, while on maintenance immunosuppression doses. Diagnosis can be made in the following ways $[3 \bullet$ :

- Fasting glucose $\geq 126 \mathrm{mg} / \mathrm{dL}$ ( $7 \mathrm{mmol} / \mathrm{L}$ ) on more than one occasion

- Random glucose $\geq 200 \mathrm{mg} / \mathrm{dL}$ ( $11.1 \mathrm{mmol} / \mathrm{L})$ with symptoms

- Oral glucose tolerance test where $2 \mathrm{~h}$ glucose $\geq 200 \mathrm{mg} / \mathrm{dL}$ $(11.1 \mathrm{mmol} / \mathrm{L})$

While hemoglobin $\mathrm{A} 1 \mathrm{C}$ is allowed for diagnosis in non-transplant patients, it is not reliable for diagnosis of PTDM in the first year after transplant so should not be used for screening in the absence of other testing

Immunosuppressants One of the most significant contributing factors to hyperglycemia in the hospitalized transplant patient is the immunosuppression required by transplantation. Corticosteroids have been long recognized to contribute to hyperglycemia by causing or exacerbating insulin resistance and increasing hepatic gluconeogenesis [17, 25, 26]. High-dose corticosteroids are commonly prescribed with induction, or to treat rejection or graft-versus-host disease, as after bone marrow transplant, in addition to being part of their longterm immunosuppression for many. Other types of immunosuppressant agents also contribute to hyperglycemia including the calcineurin inhibitors (tacrolimus more than cyclosporine) and inhibitors of the mammalian target of rapamycin (mTOR), such as sirolimus. Tacrolimus can reduce insulin secretion, increase islet apoptosis, and exacerbate insulin resistance [27-30]. Calcineurin-sparing strategies have also been shown to be associated with less risk of PTDM and better graft survival in a meta-analysis of 56 randomized control trials [31•]. Sirolimus has been shown to be independently associated with PTDM, in a large cohort of kidney transplant recipients in the US Renal Data System [32]. A separate retrospective analysis of treatment regimens also demonstrated that sirolimus predisposes to PTDM after kidney transplantation [33•]. Studies in vitro show that sirolimus disrupts insulin action through multiple effects on the insulin signal transduction pathway and can reduce beta cell function and islet mass [28, 32, 34-36].

Nutrition Nutritional support, often required immediately after both solid organ and bone marrow transplants, can also impact glycemic control, with or without a history of diabetes [37]. Total parenteral nutrition (TPN) is required after all small bowel transplants, often needed for management of graftversus-host disease after bone marrow transplant which affects intestinal function [38, 39], and commonly used posttransplant for other solid organ recipients when enteral nutrition is contraindicated for an extended period of time. TPN can cause hyperglycemia in all populations, and risk is greater 
for those with significant insulin resistance, which describes many organ transplant recipients.

Infection Immunosuppression increases risk for infections of all kinds after transplant [40], and severe infection, particularly sepsis, can precipitate hyperglycemia even in those patients with otherwise normal glucose tolerance [41]. Preexisting chronic infections like hepatitis $\mathrm{C}$ or cytomegalovirus, more common to some transplant populations, also increase risk of hyperglycemia [42].

Improved Renal Function Insulin requirements of diabetes patients decrease as renal disease progresses, due to reduced insulin degradation in the kidney [43]. Thus, after successful kidney transplant, insulin clearance by the kidney improves, unmasking preexisting glucose intolerance to contribute to the hyperglycemia observed in the immediate post-operative setting [44].

\section{Long-Term Consequences of Perioperative Glucose Control}

Patient and Graft Survival Glucose control improves outcomes for many groups of non-transplant hospitalized patients [45-50] PTDM, whether originating before or immediately after transplant, also reduces overall graft and patient survival after kidney transplant $[51,52]$. There is also increasing recognition that perioperative glycemic control alone impacts outcomes after transplant even in the absence of PTDM, possibly because of its associated risk of ischemia reperfusion and delayed graft function after kidney transplant $[53 \bullet, 54 \bullet]$. Graft rejection is also more frequent in kidney transplant recipients with post-operative hyperglycemia, whether or not they have diabetes [55-58]. In a retrospective review of liver and liverkidney transplant recipients, patients with higher postoperative glucose levels (more than $200 \mathrm{mg} / \mathrm{dL}$ ) had a higher rejection rate compared to those with glucose levels less than $200 \mathrm{mg} / \mathrm{dL}$ [56].

Hyperglycemia was associated with increased risk of mortality in liver transplant recipients [59]. However, to date, no studies suggest a benefit of perioperative glycemic control beyond that recommended for all hospitalized patients on mortality after kidney transplant [60•].

Risk for Infection In a retrospective analysis, Van den Berg et al. reported no correlation between post-operative blood glucose levels and rates of post-kidney transplant infections [61]. However, a separate retrospective analysis revealed an increased risk of rehospitalizations for infectious complications in kidney transplant recipients who developed postoperative hyperglycemia [62]. Since the rate of post- operative hyperglycemia in this population (defined as two blood glucose values $>126 \mathrm{mg} / \mathrm{dL}$ ) was quite low at $7.6 \%$, this study may not be representative of other kidney transplant populations or centers. Thomas et al. reported a significantly higher rate of infections in kidney transplant recipients who developed hyperglycemia (blood glucose $>200 \mathrm{mg} / \mathrm{dL}$ ) in the first $100 \mathrm{~h}$ post-operatively, again suggesting that postoperative hyperglycemia may be associated with increased risk for infections [57].

In liver transplant recipients, Ammori and colleagues reported a positive association between intraoperative glucose $>150 \mathrm{mg} / \mathrm{dL}$ and infection rate at 30 days when compared to an intensive glucose control group $(<150 \mathrm{mg} / \mathrm{dL})$ [59]. Park and associates also reported that in patients undergoing liver transplantation, severe intraoperative hyperglycemia $(>200 \mathrm{mg} / \mathrm{dL})$ was associated with increased risk of postoperative surgical site infection when compared to those with mean blood glucose $\leq 180 \mathrm{mg} / \mathrm{dL}$ [63].

Post-Transplant Diabetes Mellitus Those with higher glucose values after transplant are also more likely to be given a diagnosis of PTDM, as suggested by a retrospective review of liver transplant recipients. Elevated fasting glucose during the first 2 weeks was also associated with a greater incidence of diabetes after transplant [64]. Conversely, early tight glycemic control after kidney transplant with insulin may actually reduce risk of later PTDM [5•].

\section{Glucose Goals and General Approach}

Glucose goals for the hospitalized transplant patient should be the same as other hospitalized patients (ICU 140-180 mg/dL and non-ICU premeal $<140$ and random $<180 \mathrm{mg} / \mathrm{dL}$ ) [45]. The one randomized control study of kidney transplant recipients designed to assess the impact of tighter control during the immediate hospitalization ( $70-110$ vs $<180 \mathrm{mg} / \mathrm{dL})$ did not improve any outcome, and the intensive group experienced not only more hypoglycemia but also more rejection episodes, although the latter was not statistically significant [60•]. While it might be tempting to assume that tighter control would improve outcomes after heart transplant, in particular, there are no published studies. Thus, to date, more stringent glucose control could result in worse rather than better outcomes after transplant.

Treatment of hyperglycemia immediately after transplant is generally initiated with and often requires an intravenous insulin infusion algorithm with frequent glucose monitoring. Many types of intravenous insulin protocols can successfully achieve desired glucose goals, including algorithms that are nursing-driven [65]. When the patient is ready for enteral or parenteral nutrition, the intravenous insulin infusion should be 
transitioned to subcutaneous insulin injections appropriate to their insulin requirements on the intravenous insulin infusion, planned size and frequency of meals, if eating, or planned parenteral or enteral tube feeding orders.

The insulin treatment regimen required at the time of transition is highly variable so does not readily lend itself to a fixed insulin per kilogram dose, in part, because of the variation in kidney function, immunosuppression regimen, corticosteroid and other immunosuppressant doses required, severity of obesity, and other factors that drive insulin resistance in this group. If the patient is being given total parenteral nutrition (TPN), $80 \%$ of the intravenous insulin requirements over the last $24 \mathrm{~h}$ are usually administered as either neutral protamine Hagedorn (NPH) (1/3 delivered every $8 \mathrm{~h}$ ) or glargine (either as a once daily dose or split with half given every $12 \mathrm{~h}$ ). The first dose of long-acting insulin should be given at least two and preferably $4 \mathrm{~h}$ before the intravenous insulin is discontinued. If daily insulin requirements are decreasing rapidly, the daily requirements may be better estimated from that used in the last $8 \mathrm{~h}$ and multiplying by 3 to obtain the starting daily dose. After transitioning to subcutaneous insulin injections, glucose should be measured at the bedside at regular intervals, either every 4 or $6 \mathrm{~h}$, with a scale provided to guide the administration of supplemental subcutaneous regular or fast-acting analog insulin. While there is no one standard, a starting point is often $1-2$ units for every $40-50 \mathrm{mg} / \mathrm{dL}$ above a defined glucose threshold value, that value being $150 \mathrm{mg} / \mathrm{dL}$ in our center.

Insulin requirements can change dramatically when transitioning off TPN, so insulin requirements should either be reassessed off TPN before transitioning to subcutaneous insulin or a weight-based dose of insulin should be calculated (0.2-0.4 units $/ \mathrm{kg}$ ), of which $50 \%$ should be used as the starting basal insulin dose, whether the patient is being started on enteral tube feeding or meals. Fast-acting insulin is then used for bolus tube feedings or for meals, usually ordered as a ratio of fast-acting insulin/grams of carbohydrates (e.g., 1-2 units/ $15 \mathrm{~g}$ as a starting dose). Again, a supplemental scale of fast-acting insulin should be provided to address blood glucose values higher than the desired range. When reliability of food ingestion is a concern, as with frequent vomiting, the dose should be given only after it is clear what the patient actually ate and kept down, not based on what is ordered.

If the patient is not on TPN and is being transitioned from clear liquids to full diet, $80 \%$ of the intravenous insulin requirements over the last $24 \mathrm{~h}$ are usually given as basal insulin, most often as glargine or Levemir, with fast-acting insulin ordered for ingested food based on an insulin/ carbohydrate ratio, as described above.

An additional fixed dose of NPH or glargine (e.g., 10 units) is often added to cover intermittent corticosteroid doses given for induction or acute rejection to minimize glucose excursions from this dose alone. Whenever possible, coordinating the timing of glucocorticosteroid dose, whether planned for oral or intravenous administration, with that of the long-acting insulin will improve the ability to titrate the insulin dose to cover the possible increased requirements over that interval. When changing to subcutaneous insulin dosing, glucose testing frequency and supplemental insulin orders should also be adjusted to the timing of the subcutaneous insulin injections. Insulin doses should be adjusted daily based on the evidence of increasing or decreasing insulin resistance, planned changes in immunosuppression dosing, significant change in kidney function, or planned changes in nutrition strategy.

A multidisciplinary approach is essential to the management of transplant patients. Regular conversations between the glucose monitoring team with the nursing staff should reinforce a need for rapid communication of any planned or unplanned changes in immunosuppression; type, timing, frequency, or discontinuation of nutrition therapy; or planned surgery.

Diabetes education should be considered early, to include glucose monitoring and even insulin administration training, as intermittent use of insulin is common enough that early training may prevent a delay in discharge. When discharge is imminent, some can be considered for oral hypoglycemic agents if insulin requirements are low or to simplify therapy if there is concern that the patient or the family is having difficulty in handling glucose monitoring and/or insulin therapy after discharge. There are few available studies to assess safety or risk of most oral hypoglycemic agents in transplant patients, and there are greater potential risks for many oral agents as outlined in Table 2.

\section{Transplant-Specific Considerations}

Kidney Transplantation Frequent and sometimes severe shifts in renal function are common in this population and can cause rapid changes in insulin requirements. This can occur in the immediate post-transplant hospitalization, as well.

Liver Transplantation Those being transplanted for hepatitis C, particularly if on a tacrolimus-containing regimen, are much more likely to develop significant hyperglycemia after transplant [66]. A retrospective review of patients who underwent liver transplantation concluded that post-operative infections were also lower in patients on insulin infusions managed by a glucose management service where average peri-operative glucose was $158 \mathrm{mg} / \mathrm{dL}$, compared to those not on the glucose management service where average glucose was $189 \mathrm{mg} / \mathrm{dL}$ $[67 \bullet]$.

Heart Transplantation Diabetes used to be a contraindication to heart transplant, but programs generally do not exclude 
Table 2 Special considerations for use of oral and subcutaneous hypoglycemic agents in transplant patients

\begin{tabular}{|c|c|}
\hline Diabetes medication class & Potential restrictions or considerations \\
\hline $\begin{array}{l}\text { Sulfonylureas or } \\
\text { repaglinide }\end{array}$ & $\begin{array}{l}\text { Risk of hypoglycemia if GFR is reduced, } \\
\text { less with repaglinide than sulfonylureas; } \\
\text { potential drug-drug interactions of } \\
\text { sulfonylureas with cyclosporine }\end{array}$ \\
\hline Metformin & $\begin{array}{l}\text { Should not be used in the hospital or } \\
\text { within } 48 \text { h of intravenous contrast } \\
\text { administration, known heart failure, } \\
\text { elevated liver function tests, or reduced } \\
\text { GFR }\end{array}$ \\
\hline DPP-IV inhibitors & $\begin{array}{l}\text { Has not been studied with GFR }<40 \mathrm{~mL} / \\
\text { min; linagliptin least likely to require } \\
\text { dose adjustment for low GFR }\end{array}$ \\
\hline Thiazolidinediones & $\begin{array}{l}\text { May be preferentially chosen for treatment } \\
\text { of fatty liver after liver transplant but } \\
\text { should generally be avoided in others } \\
\text { with elevated liver function tests, heart } \\
\text { failure, or significant peripheral edema. } \\
\text { May also reduce hemoglobin and bone } \\
\text { mass }\end{array}$ \\
\hline Acarbose & $\begin{array}{l}\text { Avoid with low GFR; less likely to be } \\
\text { effective for most transplant patients } \\
\text { because of mild benefit }\end{array}$ \\
\hline SGLT-2 inhibitors & $\begin{array}{l}\text { No studies to assure safety in transplant } \\
\text { patients; known to increase risk of } \\
\text { genitourinary tract infections in women } \\
\text { and balanitis in men so concern risk } \\
\text { would be greater with } \\
\text { immunosuppression. Because these } \\
\text { agents are known to reduce GFR and } \\
\text { can reduce blood pressure, they may } \\
\text { have a negative impact on kidney graft }\end{array}$ \\
\hline $\begin{array}{l}\text { GLP-1 agonists (e.g., } \\
\text { exenatide, liraglutide) }\end{array}$ & $\begin{array}{l}\text { These agents have not been studied in } \\
\text { transplant patients but are known to } \\
\text { reduce intestinal motility, which may } \\
\text { affect immunosuppressant } \\
\text { pharmacokinetics. Should not be used } \\
\text { with GFR }<40 \mathrm{~mL} / \mathrm{min}\end{array}$ \\
\hline
\end{tabular}

There are few studies evaluating the safety or efficacy of many diabetes therapies other than insulin. While most transplant patients will be treated with insulin while in the hospital, some may be transitioned before discharge back to other agents that they were taking prior to the hospitalization. Co-morbidities should limit their use for specific patient groups. GFR glomerular filtration rate, SGLT-2 sodium-glucose co-transporter-2

diabetes outright, and there are no significant differences in outcomes between diabetic and non-diabetic recipients [68•, 69•]. However, hyperglycemia is common even in nondiabetic heart transplant recipients.

Lung Transplantation Many lung transplant recipients are thin, so less likely to be considered at risk for diabetes, but hyperglycemia is still common. Many patients receive lung transplant for cystic fibrosis, and many have developed cystic fibrosis-related diabetes prior to, or at risk for, hyperglycemia following transplant.
Intestinal Transplant It is common that patients receiving intestinal transplant require parenteral nutrition longer, but there is little data regarding the incidence of hyperglycemia or PTDM following intestinal transplant.

Bone Marrow Transplantation The prevalence of posttransplant hyperglycemia has been reported as high as $71 \%$ after bone marrow transplantation (BMT) and appears to be at least partially dependent on whether or not patients received parenteral nutrition [70-72]. Hyperglycemia after BMT is associated with higher rates of complications, specifically need for red blood cell and platelet transfusion and delay in granulocyte and platelet engraftment times [72]. Hyperglycemia during the neutropenic period following myeloablative allogeneic BMT is also associated with higher rates of organ dysfunction, acute graft-versus-host disease (GVHD), and worse overall survival and non-relapse mortality [73].

Body mass index (BMI) and degree of hyperglycemia within the first 10 days after transplant appear to play a significant prognostic role for developing acute GVHD. A recent study showed that $14.2 \%$ of normal to overweight subjects (normal BMI 21-24.9; overweight BMI 25-29.9) developed severe hyperglycemia within 10 days of allogeneic BMT (glucose $>9.99 \mathrm{mmol} / \mathrm{L}$ ), which significantly increased their risk of acute GVHD. More obese (BMI $>30 \mathrm{~kg} / \mathrm{m}^{2}$ ) and no lean (BMI $<21 \mathrm{~kg} / \mathrm{m}^{2}$ ) developed severe hyperglycemia, but the risk of GVHD was unrelated to severe hyperglycemia [74•].

Because skin swelling can be severe in some patients with GVHD, if subcutaneous insulin appears to be inadequately absorbed, intravenous insulin infusion may be required, as well as to achieve glucose goals in the setting of high-dose corticosteroids or with TPN. In some protocols, TPN is given as a 20-h infusion, which can be difficult to match with intravenous insulin.

\section{Current Strategies for Prevention of PTDM}

Hyperglycemia is likely to be a risk with any large surgery and cannot be completely avoided. However, there is considerable interest in reducing severity of hyperglycemia and strategies that might reduce the longer-term risk of developing PTDM. Some of these approaches are described below.

Choosing Immunosuppression Regimens Based on Diabetes Risk PTDM can reduce graft and patient survival, but rejection is the number one cause of reduced graft and patient survival [75]. Since graft survival remains the most important outcome overall, the immunosuppression regimen should be selected solely based on reducing graft failure, not diabetes risk. 
Designing Immunosuppressants or Regimens with Less Risk of PTDM Steroid-free regimens were first developed with the hope of reducing risk of PTDM but have not been associated with lower rates of PTDM because non-steroidal immunosuppressive agents also contribute to PTDM. Developing immunosuppression agents or regimens with less risk of PTDM is still a goal for many manufacturers and transplant teams.

Preventing PTDM with Hypoglycemic Agents or Insulin Multiple trials are in progress to determine if early introduction of hypoglycemic therapies can protect islets and prevent later PTDM, including dipeptidyl peptidase (DPP)-IV inhibitors, metformin, and insulin.

DPP-IV inhibitors and metformin are used for management of PTDM so are also attractive agents for prevention of PTDM $[76 \bullet, 77 \bullet, 78 \bullet$. Thiazolidinediones (TZD) have been shown to be safe and efficacious in the management of diabetes after kidney transplantation [79, 80], but the potential side effects of TZDs have not made it an attractive prevention agent. Insulin has been studied in the prevention of PTDM, and basal insulin has been shown to decrease incidence of PTDM after kidney transplant [5•]. Metformin use can be difficult in the first year after kidney transplantation due to fluctuations in creatinine but is being studied for prevention.

Preventing PTDM with Behavioral Interventions Intensive lifestyle change can prevent type 2 diabetes in at risk nontransplant populations so has been suggested as a method to prevent PTDM. Active lifestyle modification including dietitian referral, exercise program, and weight loss advice benefits kidney transplant recipients with impaired glucose tolerance [81] and should be incorporated into any preventive measure.

\section{Summary and Conclusions}

Hyperglycemia is common immediately after solid organ transplant and predicts greater risk for PTDM. Management of hyperglycemia in the immediate post-operative period is challenging because transplant recipients often have reduced or changing kidney function, experience unpredictable changes in nutrition due to nausea and vomiting and frequent need for parenteral and enteral nutrition, require treatment with types and doses of immunosuppression agents that can dramatically impact glucose intolerance, and have other events like surgery and infections or pain that can aggravate preexisting insulin resistance. Glucose goals in the hospital are the same for transplant recipients as any other hospitalized patient, but transplant recipients are at greater risk for hypoglycemia because of the frequent and potentially rapid changes in factors that impact glucose (renal function, nutrition, "stress," and medications). It is critical that all consulting teams work together as well as with the nursing team to anticipate and rapidly respond to any changes in status that might warrant a change in intravenous insulin protocol or other pharmacologic therapy. Planning for discharge is even more important than other hospitalized patients, as ongoing changes in insulin resistance can continue to occur very rapidly. The patient needs to understand when and how to contact the team if significant changes in glucose, high or low, occur after discharge.

\section{Compliance with Ethics Guidelines}

Conflict of Interest Brian Boerner, Vijay Shivaswamy, Whitney Goldner, and Jennifer Larsen declare that they have no conflict of interest.

Human and Animal Rights and Informed Consent This article does not contain any studies with human or animal subjects performed by any of the authors.

Open Access This article is distributed under the terms of the Creative Commons Attribution License which permits any use, distribution, and reproduction in any medium, provided the original author(s) and the source are credited.

\section{References}

Papers of particular interest, published recently, have been highlighted as:

- Of importance

1. Pei D, Chen TW, Kuo YL, et al. The effect of surgical stress on insulin sensitivity, glucose effectiveness and acute insulin response to glucose load. J Endocrinol Investig. 2003;26:397-402.

2. Davidson J, Wilkinson A, Dantal J, et al. New-onset diabetes after transplantation: 2003 international consensus guidelines. Proceedings of an international expert panel meeting. Barcelona, Spain, 19 February 2003. Transplantation. 2003;75:SS3-24.

3. Sharif A, Hecking M, de Vries AP, et al. Proceedings from an international consensus meeting on posttransplantation diabetes mellitus: recommendations and future directions. Am J Transplant. 2014;14:1992-2000. Recommended changes in diagnosis of post-transplant diabetes and update in current contributing causes.

4. Chakkera HA, Knowler WC, Devarapalli Y, et al. Relationship between inpatient hyperglycemia and insulin treatment after kidney transplantation and future new onset diabetes mellitus. Clin J Am Soc Nephrol: CJASN. 2010;5:1669-75.

5. Hecking M, Haidinger M, Doller D, et al. Early basal insulin therapy decreases new-onset diabetes after renal transplantation. J Am Soc Nephrol: JASN. 2012;23:739-49. Evidence suggesting early glucose control in hospitalization for kidney transplant improves later risk of diabetes.

6. . "National Diabetes Statistics Report (Centers for Disease Control and Prevention)." Available at: http://www.cdc.gov/diabetes/pubs/ statsreport14.htm Retrieved July 11, 2014.

7. Garcia-Compean D, Jaquez-Quintana JO, Gonzalez-Gonzalez JA, Maldonado-Garza H. Liver cirrhosis and diabetes: risk factors, 
pathophysiology, clinical implications and management. World $\mathrm{J}$ Gastroenterol: WJG. 2009;15:280-8.

8. Russo MJ, Chen JM, Hong KN, et al. Survival after heart transplantation is not diminished among recipients with uncomplicated diabetes mellitus: an analysis of the United Network of Organ Sharing database. Circulation. 2006;114:2280-7.

9. Czerny M, Sahin V, Fasching P, et al. The impact of diabetes mellitus at the time of heart transplantation on long-term survival. Diabetologia. 2002;45:1498-508.

10. Klingenberg R, Gleissner C, Koch A, et al. Impact of pre-operative diabetes mellitus upon early and late survival after heart transplantation: a possible era effect. J Heart Lung Transplant: Off Publ Int Soc Heart Transplant. 2005;24:1239-46.

11. Lang CC, Beniaminovitz A, Edwards N, Mancini DM. Morbidity and mortality in diabetic patients following cardiac transplantation. J Heart Lung Transplant: Off Publ Int Soc Heart Transplant. 2003;22:244-9.

12. Dare AJ, Plank LD, Phillips AR, et al. Additive effect of pretransplant obesity, diabetes, and cardiovascular risk factors on outcomes after liver transplantation. Liver Transplant: Off Publ Am Assoc Study Liver Dis Int Liver Transplant Soc. 2014;20:281-90.

13. Younossi ZM, Stepanova M, Saab S, et al. The impact of type 2 diabetes and obesity on the long-term outcomes of more than 85 000 liver transplant recipients in the US. Aliment Pharmacol Ther. 2014;40(6):686-94. doi: 10.1111/apt.12881. Impact of diabetes and obesity on liver transplant outcomes.

14. Friedman AN, Miskulin DC, Rosenberg IH, Levey AS. Demographics and trends in overweight and obesity in patients at time of kidney transplantation. Am J Kidney Dis: Off J Natl Kidney Found. 2003;41:480-7.

15. Baum CL. Weight gain and cardiovascular risk after organ transplantation. JPEN J Parenter Enteral Nutr. 2001;25:114-9.

16. Oterdoom LH, de Vries AP, Gansevoort RT, et al. Determinants of insulin resistance in renal transplant recipients. Transplantation. 2007;83:29-35.

17. Chakkera HA, Weil EJ, Castro J, et al. Hyperglycemia during the immediate period after kidney transplantation. Clin J Am Soc Nephrol: CJASN. 2009;4:853-9.

18. Kamar N, Mariat C, Delahousse M, et al. Diabetes mellitus after kidney transplantation: a French multicentre observational study. Nephrol Dial Transpl: Off Publ Eur Dial Transplant Assoc Eur Ren Assoc. 2007;22:1986-93.

19. Pageaux GP, Faure S, Bouyabrine H, Bismuth M, Assenat E. Longterm outcomes of liver transplantation: diabetes mellitus. Liver Transplant: Off Publ Am Assoc Study Liver Dis Int Liver Transplant Soc. 2009;15 Suppl 2:S79-82.

20. Sulanc E, Lane JT, Puumala SE, et al. New-onset diabetes after kidney transplantation: an application of 2003 International Guidelines. Transplantation. 2005;80:945-52.

21. Valderhaug TG, Jenssen T, Hartmann A, et al. Fasting plasma glucose and glycosylated hemoglobin in the screening for diabetes mellitus after renal transplantation. Transplantation. 2009;88:429-34.

22. Vincenti F, Friman S, Scheuermann E, et al. Results of an international, randomized trial comparing glucose metabolism disorders and outcome with cyclosporine versus tacrolimus. Am J Transplant: Off J Am Soc Transplant Am Soc Transplant Surg. 2007;7:1506-14.

23. Ye X, Kuo HT, Sampaio MS, et al. Risk factors for development of new-onset diabetes mellitus in adult heart transplant recipients. Transplantation. 2010;89:1526-32.

24. Sharif A, Baboolal K. Diagnostic application of the $\mathrm{A}(1 \mathrm{c})$ assay in renal disease. J Am Soc Nephrol: JASN. 2010;21:383-5.

25. Mathew JT, Rao M, Job V, Ratnaswamy S, Jacob CK. Post-transplant hyperglycaemia: a study of risk factors. Nephrol Dial Transplant: Off Publ Eur Dial Transplant Assoc Eur Ren Assoc. 2003;18:164-71.

26. Mathis AS, Liu MT, Adamson RT, Nambi SS, Patel AM. Retrospective analysis of early steroid-induced adverse reactions in kidney and kidney-pancreas transplant recipients. Transplant Proc. 2007;39:199-201.

27. Johnson JD, Ao Z, Ao P, et al. Different effects of FK506, rapamycin, and mycophenolate mofetil on glucose-stimulated insulin release and apoptosis in human islets. Cell Transplant. 2009;18:833-45.

28. Oetjen E, Baun D, Beimesche S, et al. Inhibition of human insulin gene transcription by the immunosuppressive drugs cyclosporin A and tacrolimus in primary, mature islets of transgenic mice. Mol Pharmacol. 2003;63:1289-95.

29. Radu RG, Fujimoto S, Mukai E, et al. Tacrolimus suppresses glucoseinduced insulin release from pancreatic islets by reducing glucokinase activity. Am J Physiol Endocrinol Metab. 2005;288:E365-71.

30. Redmon JB, Olson LK, Armstrong MB, Greene MJ, Robertson RP. Effects of tacrolimus (FK506) on human insulin gene expression, insulin mRNA levels, and insulin secretion in HIT-T15 cells. J Clin Invest. 1996;98:2786-93.

31. Sharif A, Shabir S, Chand S, et al. Meta-analysis of calcineurininhibitor-sparing regimens in kidney transplantation. J Am Soc Nephro: JASN. 2011;22:2107-18. Impact of calcineurin inhibitorsparing regimens on post-transplant diabetes.

32. Johnston O, Rose CL, Webster AC, Gill JS. Sirolimus is associated with new-onset diabetes in kidney transplant recipients. J Am Soc Nephrol: JASN. 2008;19:1411-8.

33. Gyurus E, Kaposztas Z, Kahan BD. Sirolimus therapy predisposes to new-onset diabetes mellitus after renal transplantation: a longterm analysis of various treatment regimens. Transplant Proc. 2011;43:1583-92. Impact of sirolimus on post-transplant diabetes.

34. Fraenkel M, Ketzinel-Gilad M, Ariav Y, et al. mTOR inhibition by rapamycin prevents beta-cell adaptation to hyperglycemia and exacerbates the metabolic state in type 2 diabetes. Diabetes. 2008;57:945-57.

35. Larsen JL, Bennett RG, Burkman T, et al. Tacrolimus and sirolimus cause insulin resistance in normal Sprague Dawley rats. Transplantation. 2006;82:466-70.

36. Teutonico A, Schena PF, Di Paolo S. Glucose metabolism in renal transplant recipients: effect of calcineurin inhibitor withdrawal and conversion to sirolimus. J Am Soc Nephrol: JASN. 2005;16:3128-35.

37. Roehl KA, Lach K, Coltman AE, et al. Predictors of insulin requirements among hospitalized adults receiving parenteral nutrition. JPEN J Parenter Enteral Nutr. 2013;37:755-62.

38. O'Keefe SJ, Emerling M, Koritsky D, et al. Nutrition and quality of life following small intestinal transplantation. Am J Gastroenterol. 2007; 102:1093-100.

39. Rzepecki P, Barzal J, Oborska S. Blood and marrow transplantation and nutritional support. Support Care Cancer: Off J Multinatl Assoc Support Care Cancer. 2010;18 Suppl 2:S57-65.

40. Dharnidharka VR, Stablein DM, Harmon WE. Post-transplant infections now exceed acute rejection as cause for hospitalization: a report of the NAPRTCS. Am J Transplant: Off J Am Soc Transplant Am Soc Transplant Surg. 2004;4:384-9.

41. Leonidou L, Michalaki M, Leonardou A, et al. Stress-induced hyperglycemia in patients with severe sepsis: a compromising factor for survival. Ame J Med Sci. 2008;336:467-71.

42. Zein CO, Levy C, Basu A, Zein NN. Chronic hepatitis C and type II diabetes mellitus: a prospective cross-sectional study. Am J Gastroenterol. 2005;100:48-55.

43. Snyder RW, Berns JS. Use of insulin and oral hypoglycemic medications in patients with diabetes mellitus and advanced kidney disease. Semin Dial. 2004;17:365-70.

44. Rabkin R, Ryan MP, Duckworth WC. The renal metabolism of insulin. Diabetologia. 1984;27:351-7.

45. American Diabetes Association. Executive summary: standards of medical care in diabetes_-2014. Diabetes Care. 2014;37 Suppl 1: S5-13.

46. Finfer S, Chittock DR, Su SY, et al. Intensive versus conventional glucose control in critically ill patients. N Engl J Med. 2009;360: 1283-97. 
47. Furnary AP, Zerr KJ, Grunkemeier GL, Starr A. Continuous intravenous insulin infusion reduces the incidence of deep sternal wound infection in diabetic patients after cardiac surgical procedures. Ann Thorac Surg. 1999;67:352-60. discussion 360-352.

48. Malmberg K. Prospective randomised study of intensive insulin treatment on long term survival after acute myocardial infarction in patients with diabetes mellitus. DIGAMI (Diabetes Mellitus, Insulin Glucose Infusion in Acute Myocardial Infarction) Study Group. BMJ. 1997;314:1512-5.

49. Malmberg K, Norhammar A, Wedel H, Ryden L. Glycometabolic state at admission: important risk marker of mortality in conventionally treated patients with diabetes mellitus and acute myocardial infarction: long-term results from the Diabetes and Insulin-Glucose Infusion in Acute Myocardial Infarction (DIGAMI) study. Circulation. 1999;99:2626-32.

50. Ishihara M, Kojima S, Sakamoto T, et al. Acute hyperglycemia is associated with adverse outcome after acute myocardial infarction in the coronary intervention era. Am Heart J. 2005;150:814-20.

51. Kasiske BL, Snyder JJ, Gilbertson D, Matas AJ. Diabetes mellitus after kidney transplantation in the United States. Am J Transplant: Off J Am Soc Transplant Am Soc Transplant Surg. 2003;3:178-85.

52. Cosio FG, Pesavento TE, Kim S, et al. Patient survival after renal transplantation: IV. Impact Post-Transplant Diabetes Kidney Int. 2002;62:1440-6.

53. Parekh J, Roll GR, Feng S, Niemann CU, Hirose R. Peri-operative hyperglycemia is associated with delayed graft function in deceased donor renal transplantation. Clin Transpl. 2013;27:E424-30. Impact of perioperative hyperglycemia on graft function after deceased kidney transplant.

54. Parekh J, Niemann CU, Dang K, Hirose R. Intraoperative hyperglycemia augments ischemia reperfusion injury in renal transplantation: a prospective study. J Transplant. 2011;2011:652458. Impact of perioperative hyperglycemia on graft function after kidney transplant.

55. Ganji MR, Charkhchian M, Hakemi M, et al. Association of hyperglycemia on allograft function in the early period after renal transplantation. Transplant Proc. 2007;39:852-4.

56. Wallia A, Parikh ND, Molitch ME, et al. Posttransplant hyperglycemia is associated with increased risk of liver allograft rejection. Transplantation. 2010;89:222-6.

57. Thomas MC, Mathew TH, Russ GR, Rao MM, Moran J. Early perioperative glycaemic control and allograft rejection in patients with diabetes mellitus: a pilot study. Transplantation. 2001;72:1321-4.

58. Thomas MC, Moran J, Mathew TH, Russ GR, Rao MM. Early perioperative hyperglycaemia and renal allograft rejection in patients without diabetes. BMC Nephrol. 2000;1:1.

59. Ammori JB, Sigakis M, Englesbe MJ, O’Reilly M, Pelletier SJ. Effect of intraoperative hyperglycemia during liver transplantation. J Surg Res. 2007;140:227-33.

60. Hermayer KL, Egidi MF, Finch NJ, et al. A randomized controlled trial to evaluate the effect of glycemic control on renal transplantation outcomes. J Clin Endocrinol Metab. 2012;97:4399-406. Glycemic control and kidney transplant outcomes.

61. van den Berg TJ, Bogers H, Vriesendorp TM, et al. No apparent impact of increased post-operative blood glucose levels on clinical outcome in kidney transplant recipients. Clin Transpl. 2009;23:256-63.

62. Hosseini MS, Nemati E, Pourfarziani V, et al. Early hyperglycemia after allogenic kidney transplantation: does it induce infections. Ann Transplant: Q Pol Transplant Soc. 2007;12:23-6.

63. Park C, Hsu C, Neelakanta G, et al. Severe intraoperative hyperglycemia is independently associated with surgical site infection after liver transplantation. Transplantation. 2009;87:1031-6.

64. Anderson AL, Lewis DA, Steinke DT, et al. Effects of hyperglycemia on the development of new-onset diabetes after liver transplantation. Prog Transplant. 2009;19:298-303.
65. Keegan MT, Vrchota JM, Haala PM, Timm JV. Safety and effectiveness of intensive insulin protocol use in post-operative liver transplant recipients. Transplant Proc. 2010;42:2617-24.

66. Sanchez-Perez B, Aranda Narvaez JM, Santoyo Santoyo J, et al. Influence of immunosuppression and effect of hepatitis $\mathrm{C}$ virus on new onset of diabetes mellitus in liver transplant recipients. Transplant Proc. 2008;40:2994-6.

67. Wallia A, Parikh ND, O'Shea-Mahler E, et al. Glycemic control by a glucose management service and infection rates after liver transplantation. Endocr Pract. 2011;17:546-51. Glycemic control and infections after liver tranpslant.

68. Garcia C, Wallia A, Gupta S, et al. Intensive glycemic control after heart transplantation is safe and effective for diabetic and nondiabetic patients. Clin Transpl. 2013;27:444-54. Glycemic control after heart transplant.

69. Wallia A, Gupta S, Garcia C, et al. Examination of implementation of intravenous and subcutaneous insulin protocols and glycemic control in heart transplant patients. Endocr Pract: Off J Am Coll Endocrinol Am Assoc Clin Endocrinol. 2014;20:527-35. Glycemic control after heart transplant.

70. Rentschler LM, Swarts SJ, Bierman PJ, et al. Association between hyperglycemia and hospital length of stay in patients undergoing hematopoietic stem cell transplantation. Endocrinologist. 2010;20:232-5.

71. Sheean PM, Braunschweig C, Rich E. The incidence of hyperglycemia in hematopoietic stem cell transplant recipients receiving total parenteral nutrition: a pilot study. J Am Diet Assoc. 2004;104:1352-60.

72. Sheean PM, Freels SA, Helton WS, Braunschweig CA. Adverse clinical consequences of hyperglycemia from total parenteral nutrition exposure during hematopoietic stem cell transplantation. Biol Blood Marrow Transplant: J Am Soc Blood Marrow Transplant. 2006;12:656-64.

73. Fuji S, Kim SW, Mori S, et al. Hyperglycemia during the neutropenic period is associated with a poor outcome in patients undergoing myeloablative allogeneic hematopoietic stem cell transplantation. Transplantation. 2007;84:814-20.

74. Gebremedhin E, Behrendt CE, Nakamura R, Parker P, Salehian B. Severe hyperglycemia immediately after allogeneic hematopoietic stem-cell transplantation is predictive of acute graft-versus-host disease. Inflammation. 2013;36:177-85. Hyperglycemia and impact on hematopoietic stem cell transplant.

75. Cole EH, Johnston O, Rose CL, Gill JS. Impact of acute rejection and new-onset diabetes on long-term transplant graft and patient survival. Clin J Am Soc Nephrol: CJASN. 2008;3:814-21.

76. Boerner BP, Miles CD, Shivaswamy V. Efficacy and safety of sitagliptin for the treatment of new-onset diabetes after renal transplantation. Int J Endocrinol. 2014;2014:617638. Safety of DPP-IV inhibitor in treatment of diabetes after kidney transplant.

77. Haidinger M, Werzowa J, Hecking M, et al. Efficacy and safety of vildagliptin in new-onset diabetes after kidney transplantation-a randomized, double-blind, placebo-controlled trial. Am J Transplant. 2013;14:115-23. Safety of DPP-IV inhibitor in treatment of diabetes after kidney transplant.

78. Sanyal D, Gupta S, Das P. A retrospective study evaluating efficacy and safety of linagliptin in treatment of NODAT (in renal transplant recipients) in a real world setting. Indian J Endocrinol Metab. 2013;17:S203-5. Safety of DPP-IV inhibitor in treatment of diabetes after kidney transplant.

79. Luther P, Baldwin Jr D. Pioglitazone in the management of diabetes mellitus after transplantation. Am J Transplant. 2004;4:2135-8.

80. Kurian B, Joshi R, Helmuth A. Effectiveness and long-term safety of thiazolidinediones and metformin in renal transplant recipients. Endocr Pract. 2008;14:979-84.

81. Sharif A, Moore R, Baboolal K. Influence of lifestyle modification in renal transplant recipients with postprandial hyperglycemia. Transplantation. 2008;85:353-8. 